\title{
DESIGN WORKSHOPS AS A TOOL FOR INFORMAL ARCHITECTURAL EDUCATION.
}

\section{Hülya Turgut, Emel Cantürk}

\begin{abstract}
Although the design studio has formally been the locus for design education, informal education approach has gained more and more acceptance in the world. Informal education, which is the education outside the confines of curricula, includes the acquisition of knowledge and skills through experience, reading, social contact, etc. Workshops cover the essential weight of this informal education. Although the role of the design workshops in architectural design education has been very limited through overall design education's past, many schools of architecture have taken steps to consider workshops as the part of informal learning and education.

"Culture and Space in the Build environment" (CSBE) Network of IAPS have been organizing "culture and design workshop series" for graduate and post graduate students in Turkey since 2001. In these workshops, a design teaching approach based on the conceptual framework of culture and space interactions is applied. The conceptual framework developed for the architectural design education, takes three fundamental starting points for workshops as the part of informal design education: as a tool for informal design education (method), as a tool for learning \& understanding culture-environment relations (content), and as a tool for awareness of different environments/contexts (scale/place). The foundation of the conceptual framework is based on the general approach that discusses the "architectural design process" with regards to environmental context and content.

Within this context the aim of the paper is to discuss and evaluate the importance and the contribution of workshops as tool for informal architectural design education. These discussions will be held on the case of IAPS-CBSE Network's last workshop "Istanbul as a Palimpsest City and Imperfection". In the paper, the process, the method, the content and the results of workshop studies will be discussed and evaluated.
\end{abstract}

Keywords: Informal Architectural Education, Workshops, Place, Istanbul, Palimpsest City.

\section{INTRODUCTION}

The Design studio is a central part of the architectural design education. It works as a method by which we demonstrate the integration and syntheses of the key themes in students' academic portfolios. Design is an iterative process, which involves research and its reflection and integration of knowledge. It takes time, space and careful mentoring to acquire the practical and mental agility, the complex interaction of skills, knowledge and creativity that is central to the practice of architectural design (Milliner, 2003). Since there are many different points of views on what constitutes architectural education, there are also a variety of methods, including different contents and scales in teaching design.

Although the design studio has formally been the locus for design education, informal education approach has gained more and more acceptance in the world. Informal education includes the acquisition of knowledge and skills through experience, reading, social contact, etc. Workshops cover the essential weight of this informal education. A workshop is a brief, but intensive group meeting offen facilitated by one or more people from several disciplines.

The role of the design workshops in architectural education has been very limited through overall design education's past, and thus has gone largely unnoticed by the educators of design. The drivers of this change in design education and practice; and changing student demographics brought some inevitable changes to design studio practices. The introduction of workshops, which aids not only developing and sharpening design skills in a short period of time, but also help to construct new approaches in architectural education. Many schools of architecture have taken steps to consider workshops as the part of informal education.

'Culture and Space in Build environment' (CSBE) Network of IAPS' have been organizing design workshop series for graduate and post graduate students in Turkey since 2001.2

In organizing these design workshop series, the main aim is to focus on architecture and culture interac-

${ }^{1}$ Coordinated by Hulya Turgut and Peter Kellett, IAPS-CSBE Network is a scientific organisation taking place within IAPS "International Association for PeopleEnvironment Studies" aiming at defining the problems arising from the interaction between the culture and the space; seeking for solutions in an interdisciplinary framework after establishing a relation between theory and implementation; including these issues in the architectural education process along with theoretical and implementation studies in the overall context of built environment, design and planning issues. IAPS webpage: http://www.iaps-association.org

2 The first one was organized in the historic town of Amasya in North Central Anatolia, entitled as "Amasya: Continuity and Change". The second workshop was organized in Trilye between 12 to 17 July 2007 entitled as "Trilye: Continuity, Change \& Transformation". The third one was organized in Istanbul between 15 to 20 February 2010 entitled as "Istanbul: The routes of Culture of Architecture". And the last one was organized within the context of the Academic Program of the 1st Istanbul Biennale, between 1 to 5 October 2012 entitled as "Istanbul as a Palimpsest City and Imperfection". 


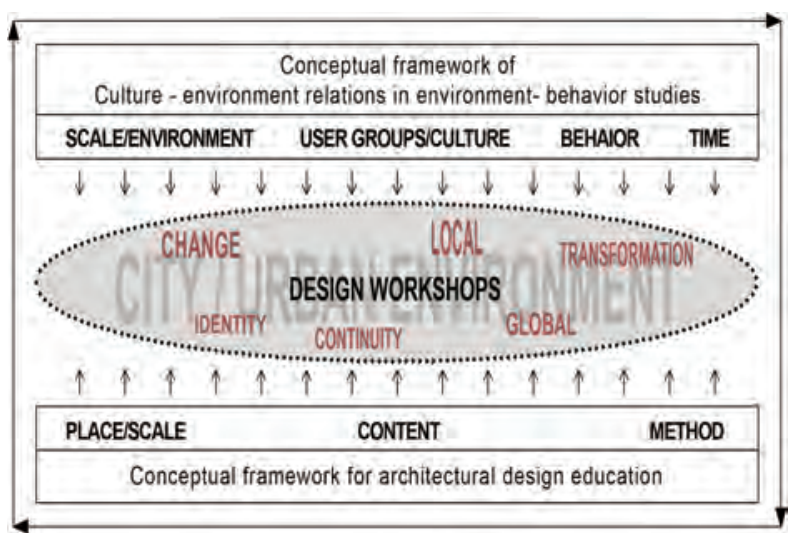

Figure 1. The conceptual framework of culture and space interactions in architectural design education (based on Turgut Yıldız \& Inalhan, 2008).

tion using the concept and theories on culture and space in architectural education. Our other aim is to form a platform for architecture students to communicate, collaborate and share their experiences and knowledge.

\section{THE CONCEPTUAL FRAMEWORK FOR THE DESIGN WORKSHOPS OF IAPS-CSBE NETWORK}

In general, and in the framework of this paper the teaching approach to the design education used by authors is based on the perspective of environment-behavior studies of which culture-environment relations are a part. Using the conceptual framework of culture and space interactions comprising the components of scale/environment, user groups/culture, behavior and time, help us to develop a conceptual framework for design education. In relation with this conceptual framework, architectural design education is a combination of three basic systems: scale/place, content, and method. Where content component consists of user groups and wider culture, scale/place component defines coverage and space and the teaching methods comprise the processes and techniques in design (Eren and Turgut, 2001; Turgut and others, 2002; Turgut Yildız, 2007, Turgut Yıldız and Inalhan, 2008). While creating this framework, the focus has not been on the typological building design, but more on 'how' to think while designing an environment in an experimental process (Figure 1).

The foundation of the conceptual framework is based on the general approach of the authors, educators and architects, discussing the 'architectural design process' with regards to environmental context and content. In the context of the conceptual framework as defined above, the examination of the environment is a starting point for theoretical considerations of the design teaching. The ability to 'read' and understand the environments in different contexts, urban forms, and building typologies is implicit in the discussion of the integrity of culture, space, and architecture. Therefore, to include field works aimed at 'reading the environment' to the design education process and taking students, either individually or as a group, to a place is very useful for the conceptual basis of teaching model. As pointed out by Bechhofer who has been taking his student abroad, students will have perceptions of the environment as well as of themselves in relation to it, in an unfamiliar context (Bechhofer, 2001).
Based on the framework and approach of authors to architectural design education, we can summarize three fundamental starting points for workshops as the part of informal design education:

- workshops as a tool for informal design education: Method (techniques \& process)

- workshops as a tool for learning \& understanding culture and environment relations (and EBS more generally): Content

- workshops as a tool for awareness of environments in different contexts/importance of place: Scale/Place

\subsection{METHOD (TECHNIQUES \&PROCESS): WORKSHOPS AS A TOOL FOR INFORMAL DESIGN EDUCATION}

The main aim of a contemporary design education is to provide process-focused education, rather than productfocused education. Process-focused design needs an inspiring atmosphere which is possible with the workshops out of studios; this is because workshops offer a free environment of interaction which is purged from constraints of formal education (Civaroğlu, 2003).

Workshops are educational tools developed to facilitate an understanding of different strategies for defining and exploring design problems, generating new ideas and making decisions towards solving them in a short period of time. It is evident that they help sharpen students' perception and accordingly design skills. As teachers and designers we know that skills learned by doing - visualization, hands-on manipulation, and modeling - are not easily forgotten. More of field visits, studios, workshops and tutorials; less of lecture courses are very essential, as the learning in architecture is predominantly sensual and perceptual.

The free atmosphere of workshops provides the medium for productivity and creativity of the students. These intensive but time limited group meetings work as an enabler to set of activities designed to promote learning, discussion and feedback by highly involvement and interaction of the participating students. The free discussions, exchange of ideas, and demonstration of methods of practical application of skills and principles by others help students to achieve collected knowledge and real life experience.

From this point of view, carrying out the architectural design workshops in different contexts expands the horizon of the students. Learning by seeing and living with the different physical and social characteristics of different areas is ever lasting experience. Since workshops serve as an anchor for this type of informal learning, it is important to encourage students to be an active learner by giving them the chance to participate, explore and be motivated about learning all dimensions of the environment in order to be creative.

\subsection{CONTENT: WORKSHOPS AS A TOOL FOR LEARNING AND UNDERSTANDING CULTURE AND ENVIRONMENT RELATIONS}

By designing workshops that cover the analysis of certain culture groups and their built environment, it is aimed to display the man and environment relationships that will provide data for design disciplines and emphasizing the socio-cultural factors affecting the formation of physical environments.

Socio-cultural aspects of environments have been a growing focus of people-environment research in 
the past decade but despite this expansion in research, architectural education does not appear to have been changed in any significant way. There are, however, a few strands in architectural education, which offer the most promise for integrating socio-cultural aspects of environments into their studies. Such strands in education include architecture programs with a regional or social-group focus, with a vernacular or social history emphasis, where research and undergraduate programs are less separated, and where there is an emphasis in theory of place and community (Low, 1992).

In the socio-cultural approach, social and cultural issues are regarded as crucial to understanding the built environment. These issues both dictate the nature of the design projects and form part of the design process. The students are encouraged to develop an awareness of environmental issues and the ability to respond these issues through their work. The emphasis has been on the process of response to social and cultural issues (Bar-eli and Oxman, 1998).

The analysis of culture-environment relationship is not a new topic of study. But using it in architectural education in the context of cities, has gained momentum in 1980s. The reason for that is, urban areas and cities in the world has experienced a fundamental social, cultural and economic transformation in past two decades. Globalization, internationalization and the rapid flow of information have played a significant role in changing cities, and its people. The multi-dimensional outcomes of this transformation have manifested themselves through the peculiarities of activity patterns, behavioral relationships, social and cultural norms, as well as architectural and urban patterns. The drivers of change have also reflections on the design education.

As Rapoport has stated "All these developments are highly relevant for understanding issues of culture change, identity, culture-environment relations, developing countries etc. Once the concept becomes available, examples are everywhere, and the concept becomes explanatory for a large number of environments" (Rapoport, 2008).

On the other hand, architects are responsible for the solution to this architectural and urban chaos. Architects are also culture-makers in the sense that they give form to our cultural ideals, beliefs and norms. They therefore are responsible for understanding the complex relationship of culture, place, and the built form. Teaching about culture and place is one useful way for integrating this understanding into design practice and education.

\subsection{PLACE/SCALE: WORKSHOPS AS A TOOL FOR AWARENESS OF DIFFERENT ENVIRONMENTS/CONTEXTS}

The significance of the concept of "place" and different urban identities in architectural design is undeniable. Therefore, for architecture students "studying, exploring and understanding all the dimensions of the environment" is crucial to be creative. Learning by exploring different physical and social characteristics of different areas is a more lasting approach than traditional methods. The design workshop set in different environments and scales provide architecture students an introduction to the significance of cultural awareness and socio-cultural sustainability issues in design. They are intended to provoke discussions regarding issues of space, time, spatial and socio-cultural change, and environmental and architectural identity.

We live in an era that contemporary cities and life styles are transformed by the impacts of globalization. Within the globalization process, rapid change in everyday life practices and the contradictions between global and local cultures create new paradigms and new dimensions about culture-space interactions in the city. Moreover, within this ongoing transformation 'culture', 'city' and 'urban life' gain new meanings and new forms. Therefore, it becomes more and more urgent understanding the relation between the place and cultural change.

While the topic of place becomes a key issue within the debate of globalization, much of the discussions focus on the idea that global flows of capital, culture and ideas threatens the local (Walker, 2001). As Rapoport stated, although cultural change is a general phenomenon, rates of change vary and change is especially rapid in developing countries where most traditional environments survive and are at risk (Rapoport, 2002). The internationalization of cities came into conflict with so-called "traditional" values, and in the confrontation, continuity with the past was broken and livable cities were destroyed. The essential humanity and the sense of place characteristic of traditional urban environments continue to be replaced by culturally and environmentally anonymous or irrelevant forms (Warfield, 2002).

In-situ experiences in settings identified by their historical or local attributes, settings that emphasize the historical and local characteristics provide students with the opportunity to increase their architectural experience by seeing and meeting the locals in their own setting.

Based on above structure and having the results of the four design workshops of the CSBE Network, purposes of the design workshop set in different environments can be summarized as follows:

- Enhancing students' cultural understanding through analyzing the socio-cultural and spatial characteristics and values changing in time

- Developing an understanding of the relationship between different scales of environmental settings and socio-cultural factors

- Developing design strategies to generate new ideas and solutions for different environments/contexts

- Understanding issues of scale: encouraging students to think about from neighborhood to urban scale

- Promoting the discussion on some important questions such as; What are the relations between place and culture, environment and behavior? What is contextual design?

- Understanding the effects of global culture and changing everyday life practices on the transformation of the cities.

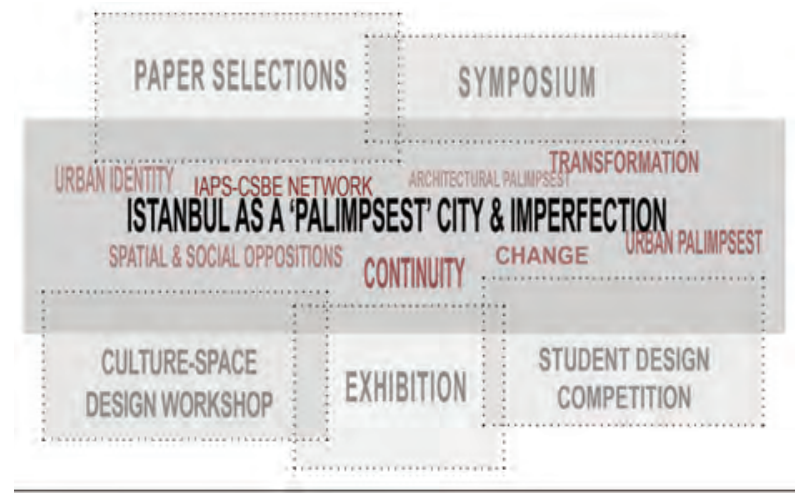

Figure 2. Intertwined activities of IAPS-CSBE Network within the 1st Istanbul Design Biennial. 


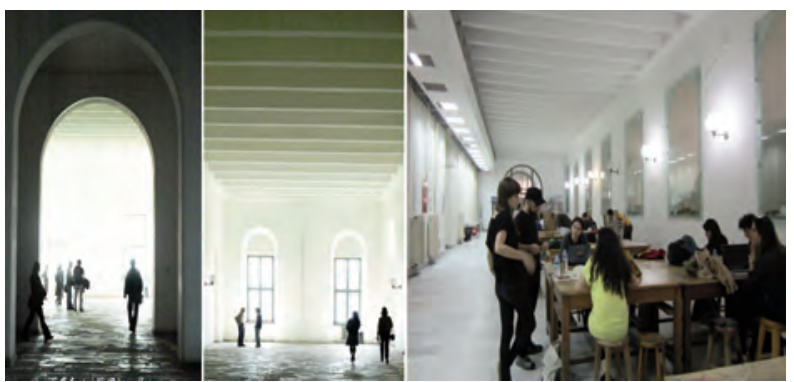

Figure 3. The Place of the Workshop: Taşkışla Building .

\section{CULTURE-SPACE DESIGN WORKSHOP OF CSBE NETWORK: ISTANBUL AS A "PALIMPSEST" CITY AND IMPERFECTION}

The first Istanbul Design Biennial with the theme of "Imperfection" took place between 13 October-12 December, 2012. The theme of "Imperfection" was attempted to be read through Istanbul during the Biennial. The expectation was for Istanbul to provide an inspiration for the design creation process with its far from being imperfect nature, fuzzy and temporary and yet exciting characteristics. ${ }^{3}$

Within the context of the Academy Program of the Biennial a number of intertwined activities such as paper selections, design workshops, student competitions, exhibitions and symposiums were jointly organised by "IAPS-CSBE Network" and the ITU, Faculty of Architecture Department of Architecture and the Department of Urban and Regional Planning. (Figure 2). ${ }^{4}$ Within the scope of these qctivities, the main aim was to analyse the "Palimpsest" 5 state of Istanbul and the discussion of concepts such as spatial and social oppositions, change, transformation, continuity, urban and architectural identity urban palimpsest within a dialectic framework.

The design workshop was held between 1 to 5 October 2012, in the campus of Istanbul Technical
University, Tasskışla with the participation of undergraduate and graduate students from many universities (Figure 3). On the basis of the conceptual framework developed in the first part of the paper, tutors from different universities $^{6}$ carried out the design workshop. The students were expected to read and interpret the multi-layered and palimpsest state of Istanbul and imperfection of its layers from their points of views and express their interpretations with a single image/poster.

In the workshop process, the tutors dwell upon not only the end products but especially on "reading and conceptualizing the city and the place".

If we emphasize the role of "place" in architectural education in the context of the workshop:

- Culture and space concepts together with spatial and social change, transformation, continuity, urban and architectural identity, urban palimpsest is being the workshop's theme (Content)

- The city chosen for the workshop is being Istanbul (Place)

- Seminars and lectures given on technical and conceptual issues and a simultaneous design process in the studio (Method)

\subsection{CONTENT: ISTANBUL AS "PALIMPSEST" CITY AND IMPERFECTION}

The multi-layered, complex and intertwined structure of Istanbul created by overlapping social, spatial, temporal layers (Figure 4) and the spatial and social transformations ongoing in Istanbul was the main theme of the workshop. It is possible to state that cities are formed of different contextual layers that are sometimes one on top of the other, sometimes side-by-side and sometimes intertwined forming its original characteristics. This formulation's most fundamental and visible element is architecture. Furthermore it can be said that the mutual interaction of the dynamics is also rapidly altering the daily life as well as the cities themselves. These transformations are resulting in new urban spaces and spatial practices. In the on-going re-structuring and transformation process, the transformational relationship between the city and architecture takes a dramatic appearance.
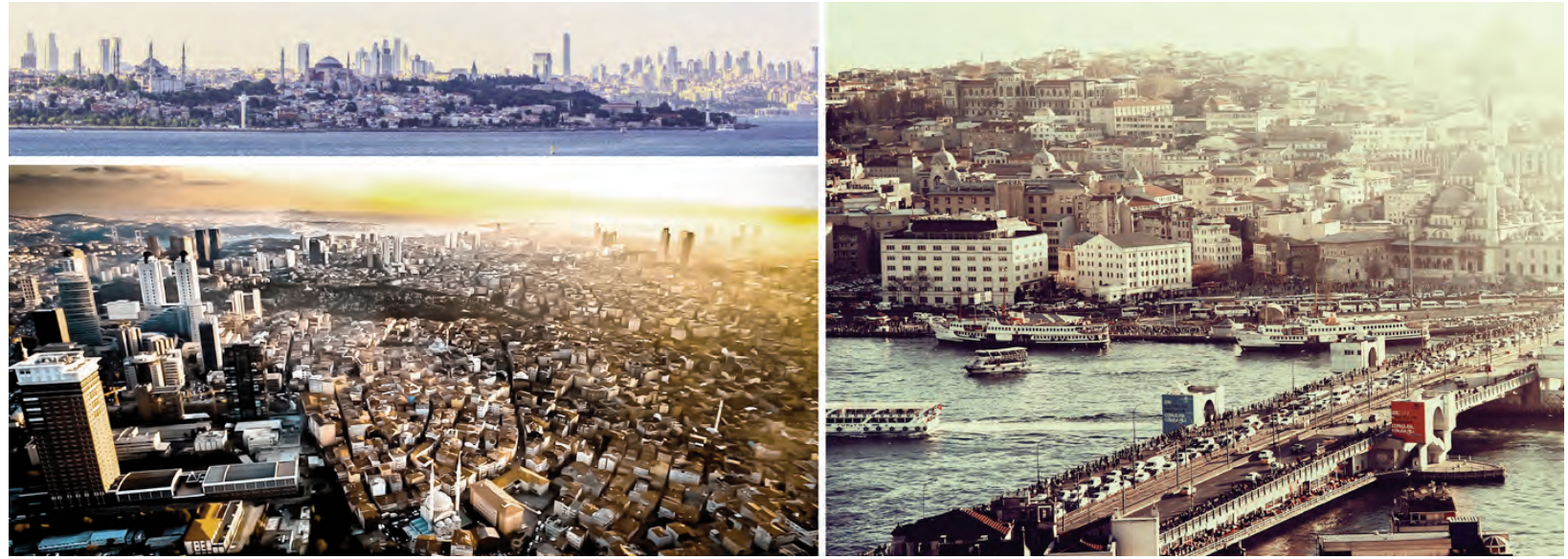

Figure 4. Istanbul as a 'Palimpsest' City; intertwined, overlapped and side-by-side spatial layers.

3http://istanbultasarimbienali.iksv.org

${ }^{4}$ Scientific Committee: Orhan Hacıhasanoğlu, ITU, IAPS-CSBE Network Founding Member; Peter Kellett, Newcastle University, IAPS-CSBE Network Co-Coordinator; Handan Türkoğlu, ITU, IAPS-CSBE Network Founding Member; Hülya Turgut, ITU,, IAPS-CSBE Network Co-Coordinator; Alper Ünlü, ITU, IAPS-CSBE Network

Founding Member. Organisation Committee: Bihter Almaç, ITÚ, Faculty of Architecture, Department of Architecture; F. Belgin Gümrü, ITU, Faculty of Architecture, Department of Urban and Regional Planning; İpek Sen, ITÚ, Faculty of Architecture, Department of Urban and Regional Planning; Önen Günöz, ITU, Faculty of Architecture, Department of Architecture; Şebnem Şoher, ITU, Faculty of Architecture, Department of Architecture.

5 Palimpsest: A manuscript or piece of writing material on which later writing has been superimposed on effaced earlier writing, but still bearing visible traces of its earlier form

TTutors: Bihter Almaç, ITU, Faculty of Architecture, Department of Architecture; Zeynep Bacınoğlu, ITU, Faculty of Architecture, Housing Research Centre; Emel Cantürk, IKU, PhD student; Işıl Ekin Çalak, MSGÚ PhD student; Önen Günöz, ITU, Faculty of Architecture, Department of Architecture; Derya Gürsel, ITU, Msc student; İlgi Hacihasanoğlu, ITỦ, Faculty of Architecture, Department of Architecture; Zelal Rahmancı, Maltepe University, Faculty of Architecture, Department of Architecture; Şebnem Şoher, ITU, Faculty of Architecture, Department of Architecture. 
In this process, spaces that are produced and reproduced continually, creates a spatial layering and this time-space accumulation becomes a basic fact that needs to be explained in the process of the analysis of urban transformation. Within this context, the following concepts of "urban palimpsest", "palimpsest identity" and "palimpsest in architecture" should be explicated.

The the multi-layered identity of Istanbul is undergoing a speedy economic, social and political transformation and the concept of urban transformation, that aims to obtain a more "perfect" appearance in various parts of Istanbul, has gained momentum in last few years. It has been occupying the national agenda since it is affecting the physical urban characteristics as well as the daily life routines. Istanbul is expected to become one of the global brand cities with a view of turning it into a source for economic prosperity by ridding it from the decrepit and turning it into a city with a perfect appearance. However, each new layer in the historical geography eliminates the physical existence of the previous one or exists by appending itself onto that previous layer. Today, the on-going transformation of Istanbul is brought about by removing the already existing, and by replacing it with the requirements of the branding process namely -the new, modern, intact, perfect.

In this context, it becomes crucial examining the intertwined relations between political and technological developments, economic structure, cultural interactions, and urban environment to understand their effects on the on the continuing transformations in Istanbul.

\subsection{METHOD: READING \& CONCEPTUALIZING THE CITY}

The workshop was designed through a parallel structure, regarding the simultaneity of the design process and the seminars given on conceptual and technical issues (Figure 5). Therefore, a design process model which proliferates and transforms through the articulation of different layers of information and perspectives to the process of design was aimed, rather than creating products through predetermined and limited perspectives.

Seminars and Discussions: During the workshop process, a number of seminars aiming to nurture the study from different points were conducted in accordance with the design process. The seminars focused on several themes such as "multi-layered structure of Istanbul", "approaches and ways of thinking that map- ping produces", "the effects of urban transformation on the "imperfect"'," "the effect of perceived space on comprehending the city", "the collective memory of the city", "the visualization of the concepts" and "phenomenological approaches".

Place Analysis/Reading the City: As a variety of approaches and methods are available for an "urban reading" intended for the discovery of the implicit situations, each workshop group has developed its own experimental method. The differentiation of the methods used is not meant to compare their success, rather it was aimed to enrich the collective experience during the workshop.

In this context, one of the methods developed was "using the metrobus line to reveal the layers of imperfection". According to this approach, folds in space are temporarily opened or closed; when they are opened the subject is associated with space, when they are closed the subject is back to his/her own layer. During the metrobus line, the subject traces the openings and closings of folds by blunting and sharpening his/her senses. The intricate layers of Istanbul constantly appearing and disappearing during the continuity of the metrobus line provide opportunities to explore about the city (Figure 6, 7).

In another method, "Sirkeci-Halkalı" rail line was used. The rail line, starting from historical peninsula, is one of the most important transportation lines of Istanbul, which links the periphery of the city to the historical centre of the city. The train passes by splitting the overlapping layers of Istanbul; and through this intersection many layers of Istanbul become visible. The perception of these different layers from the moving train creates a space-time compression. "How speed, time-space compression and layers compose and decompose the city?" Through the experience of time-space compression, it is aimed to find answers to this question.

Another approach is intended to decompose and then recombine the spatial and temporal layers of the city. In this context, the city which is composed by layers is something more than the sum of the parts or layers. Each layer is a product of a significant time and context. Therefore, contextually and temporarily differentiated layers overlap and accumulate in cities. In this manner, through diachronic and simultaneous readings carried, the aim is to understand the volumetric structure of the space better, and to decode the layers more explicitly (Figure 8, 9 and 10).

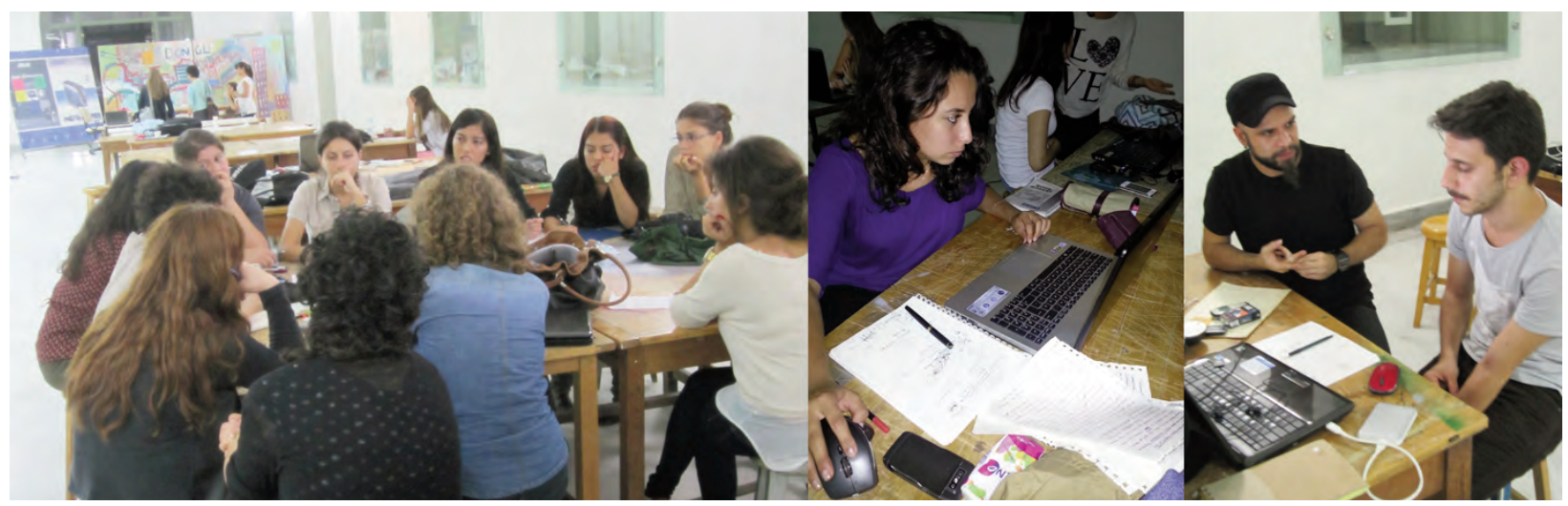

Figure 5. Discussions and design process in the studio.

7Prof. Dr. Semra Aydınlı, "Phenomenological Ways of Seeing"; Ass. Prof. Dr. Pelin Tan, "Pushing the Limits"; Ass. Prof. Dr. Zeynep Kuban, "Layered Istanbul"; Aslı Kıyak Ingin, "Imperfection and Being Multilayered through the Transformation Processes in the City Centers"; Ass. Prof. Dr. Aslihan Senel, "Mapping"; Ass. Prof. Dr. Şebnem Timur, "Perceiving the City by Senses"; Prof. Dr. Fatoş Adiloğlu, Res. Ass. Bora Fer Görsel, "Concept and Graphic Space". 
In another approach, the city has tried to be read through the different framings. Accordingly, there is connectivity between the whole and the parts/details. In reading the layered structured of the city, visible details that different framings and different scales reveal, make possible to read the invisible. In this way, the participants were expected to use different observation points of the city and to be a flaneur, in order to compare the different framings such as urban fabric captured from a high observation point or a broad Istanbul skyline photographed from the ferry and views captured from human scale.

Yet another approach was about to create series in the city. Each traveller was expected to create his/her own serie. With this method, a random reading of the layers through a serie of symbols is aimed. The

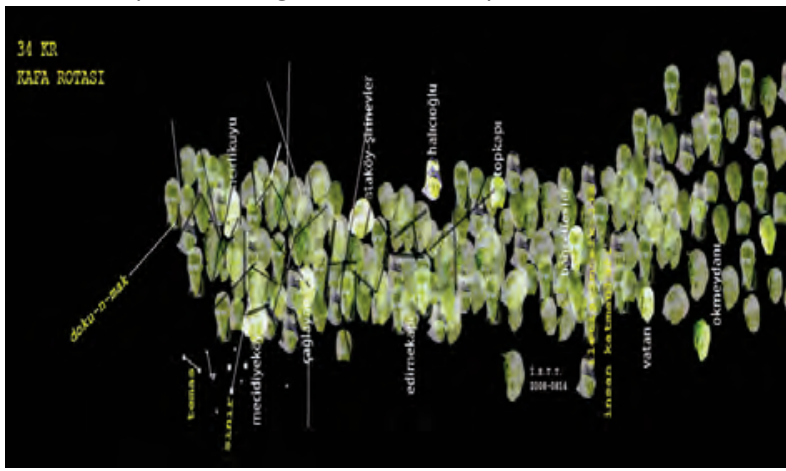

Image of Istanbul as a 'Palimpsest' City - Gözde Uyar, Bahçeşehir University, "Route of Heads: In Istanbul which is a palimpsest city, one of the most important places where layers of different people come together is the metrobus, a public transportation vehicle. People coming from different districts of the city, are dispersed to different parts of Istanbul by following different routes. People make up the various layers of the city by carrying the traces of the places where they live or come from. Despite being in close contac and nested in the city, these people coming from different layers, do not communicate with each other. Therefore, people get lost in the chaotic layers of people and get lonely inside the crowds. In this case, which situation causes imperfection to emerge? People who come from different layers and do not know each other being nested, or people being so close physically, but so apart in reality?"

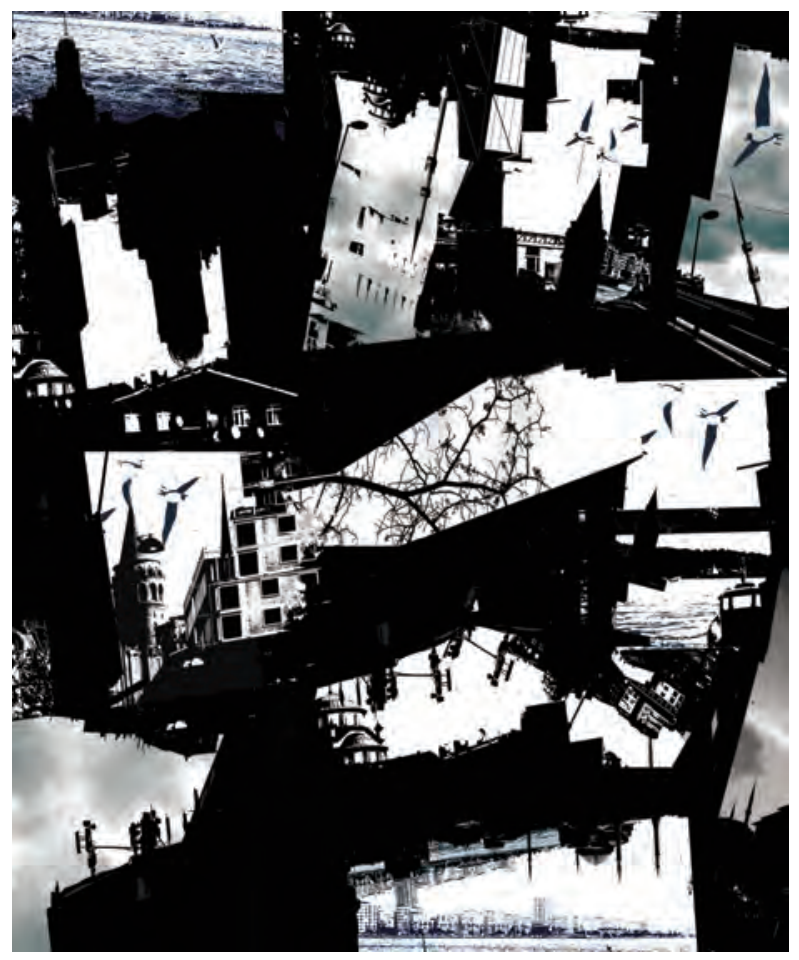

Figure 7. Image of Istanbul as a 'Palimpsest' City Püren Çetin, Bilkent University, "Image of Trash: If one could take the photograph of my brain, on the evening of the day I travelled around the streets of Istanbul, could see such images. All of these images are overlapping and stratifying in my brain and poisoning me slowly."

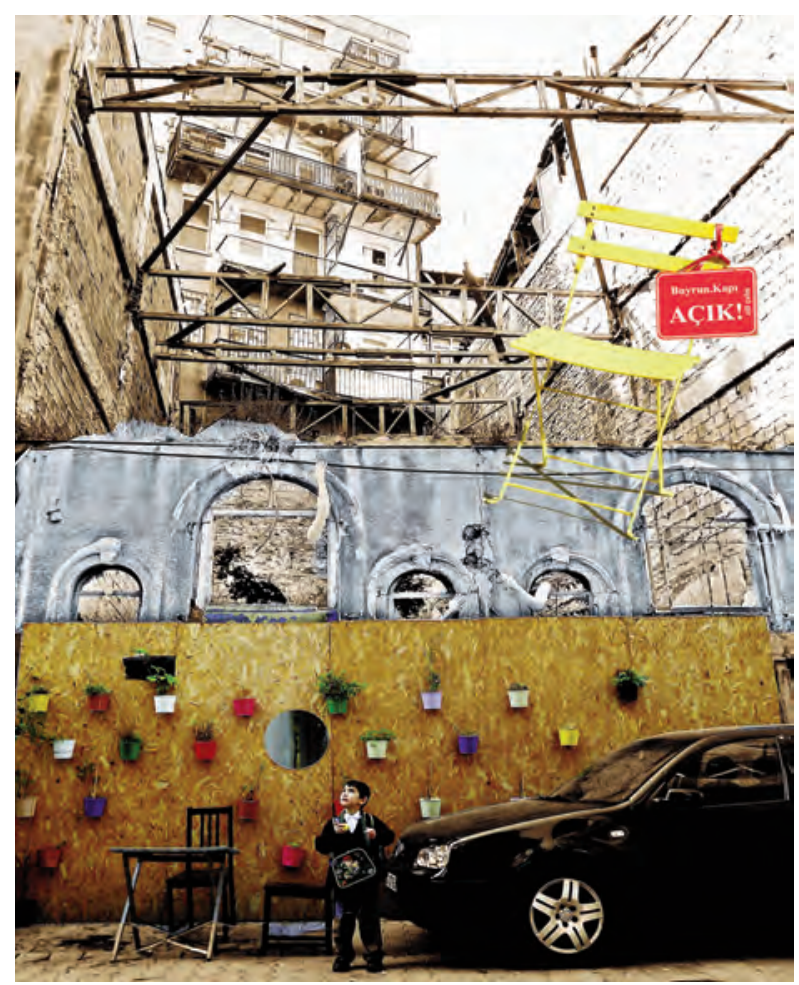

Image of Istanbul as a 'Palimpsest' City Ayşıl Coşkuner, MSGU and Gülay Özün, Işık University, "Istanbul embraces such a chaos in itself; you feel yourself almost in a surrealistic film frame. Demolished and rebuilt buildings, historical buildings, purchasings, gentrification and people stacked between all of them... Sometimes it is the memory of a street that is stucked between two buildings. Each visitor has left a trace from herself/himself here. For some, Istanbul invites us to congestion, for others, to dynamism. Come in, the door is open! Ring the bell...

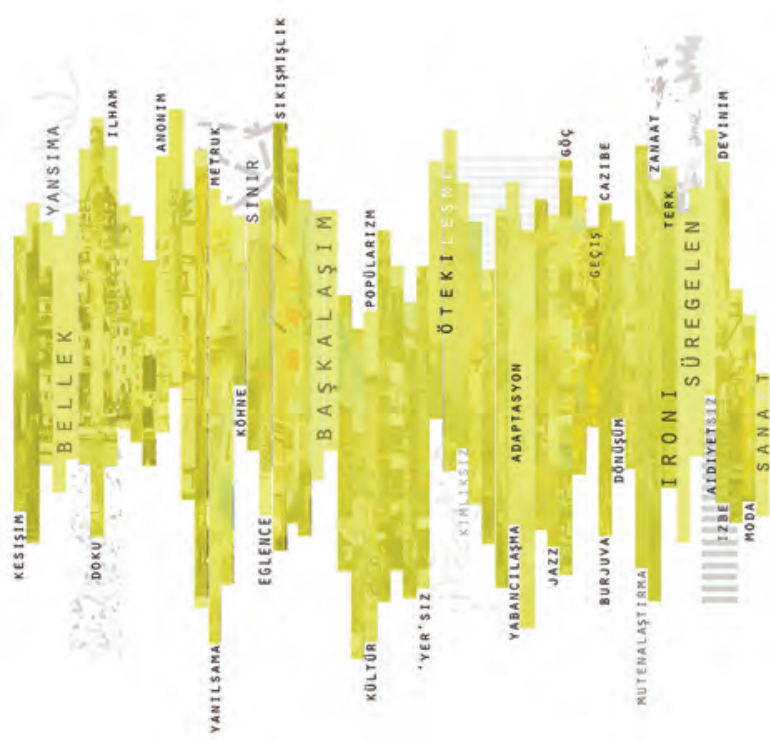

Image of Istanbul as a 'Palimpsest' City, Elif Atasoy, Maltepe University, "Istanbul s a 'Palimpsest' city is not just where we live, it is also the place where we draw lessons from the moral values of each other, where we create a sense of law and justice, and where we grasp our future through the many layers which are side-by-side or overlapped in the city. The city should be open to new varieties, new fusions and new hybrids. Beside the discourse of "gentrified (I) Galata". Galata which hosted many different typologies of people through the history, is a 'place' which still preserve its layers. Today the gentrification ongoing in Galata is in an endless process of demolition and reconstruction which causes a sterilized and fake place as a film studio."

method was determined by the city, rather than the traveller. Therefore, each traveller was asked to read the city through the randomly collected data as the parts of a single and meaningful whole.

Poster/Conceptualizing the City: Students were 


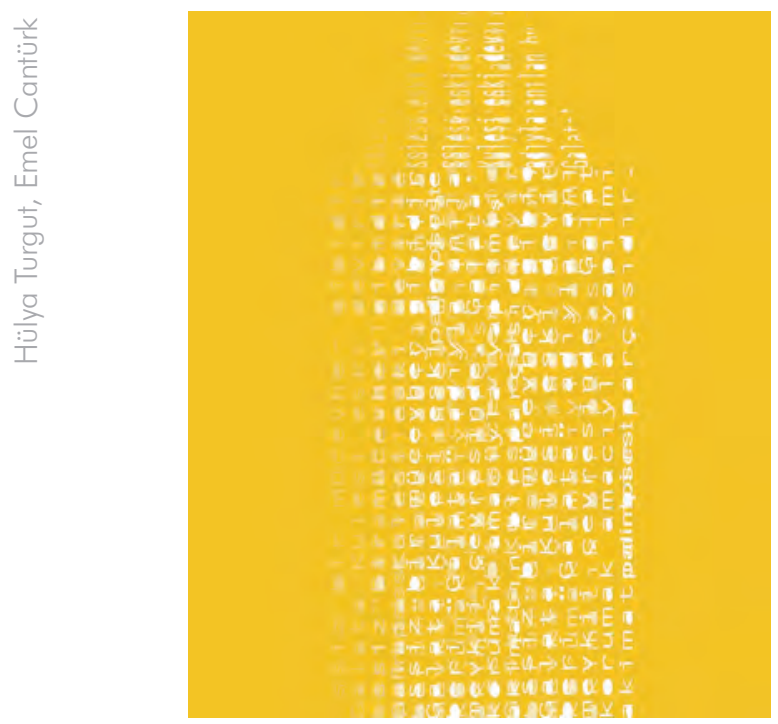

Image of Istanbul as a 'Palimpsest' City Bahar Nama, Istanbul Technical University and Nesil Suyaran, Istanbul Technical University, "Istanbul was so layered. No trace was visible anymore. This city which have never been perfect, had a self-renewing structure which accomodates the culture, diversity and dynamism in itself. But this diversity, on one hand was slowing the city down and on the other was making it transparent. All these images stored in the memory caused the identity of Istanbul to be questioned aga and again. Instead of reading this layers one by one, perhaps we should just live Istanbul within its harmony?"

asked to express their readings, interpretations and ideas with a poster as the final product of the design process. Expressing the analysis, made through an urban architectural reading, with a single image was not an easy work and it required an extremely careful and painstaking data selection process. Using and reflecting the concepts which we have attributed to urban space, without ascribing them overmuch meaning, and without losing the perspective was a challenging but also an eye-opening process.

The posters, shown below, were mostly focused on multi-layered structure of Istanbul. The participants of the workshop traced the various social and historical layers, through the routes they travelled. They emphasised the interwined, illegible and complex, but still meaningful aspect of Istanbul created by overlapping cultures.

The exhibition and presentations: At the final day of the workshop, the students were asked to give presentations and exhibit their final products. Workshop ended with a closing session organized in an historical Turkish bath building, which is contemporarily being used as a design atelier (Figure 11). In the closing session certificates were given to participants.

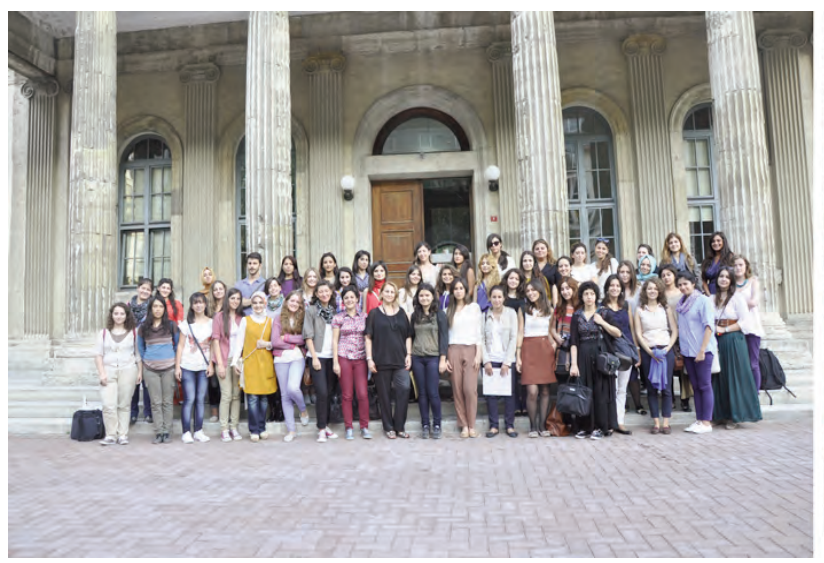

\section{CONCLUSION}

The results of the workshop demonstrate how students' interest in exchanging ideas and their willingness to work both individually and in collaboration with others in a learning environment that encouraged their curiosity, changed their attitudes towards the city. The learning process was as important as the final products in this workshop. This learning process was driven here by the concept of working in teams. The team works carried out through different methods has created a quite fruifful workshop process, in terms of enabling exchange of different teaching methods, perspectives and ideas.

Besides, the workshop taking place in an art activity such as Istanbul Design Biennial, was very beneficial for students in terms of raising their awareness about current approaches, discussions and productions in the realms of "city", "architecture", "art", and "design" in a changing and transforming world under the effects of globalization, and increasing their interest in these issues.

During the workshop process, students carried out "urban readings" intended for understanding the illegible, complex and multi-layered character of Istanbul by tracing the different social, spatial and temporal layers of the city. They have tried to understand and interpret the changing dynamics of Istanbul, and its social, temporal and spatial reflections, by developing their own viewpoints. One of the most important outcomes of the workshop was enhancing the students' understanding of the multi-layered, multi-dimensional and complex nature of "urban space" and "urban life" and encouraging them to develop their own perspectives for comprehending the city.

While the world is changing in the context of socio-cultural, physical, economic, political and technological dynamics, the cities occur to be the main places where these changes are reflected. Through the interplay of these dynamics, new everyday life practices, a new urban space, and new spatial practices emerge, therefore both the "city" and the "urban life" gain new meanings. In the context of new meanings of the city and the urban life, for architectural education the necessity to reposition itself in the light of this change is inevitable. In that respect, it is possible to say that "the city is a rich source and a research area" for architectural design education, as well as for the practice of architecture itself. The architectural design education must be aware of contemporary cultural transformation in order to approach to the city as source and resource, and to work

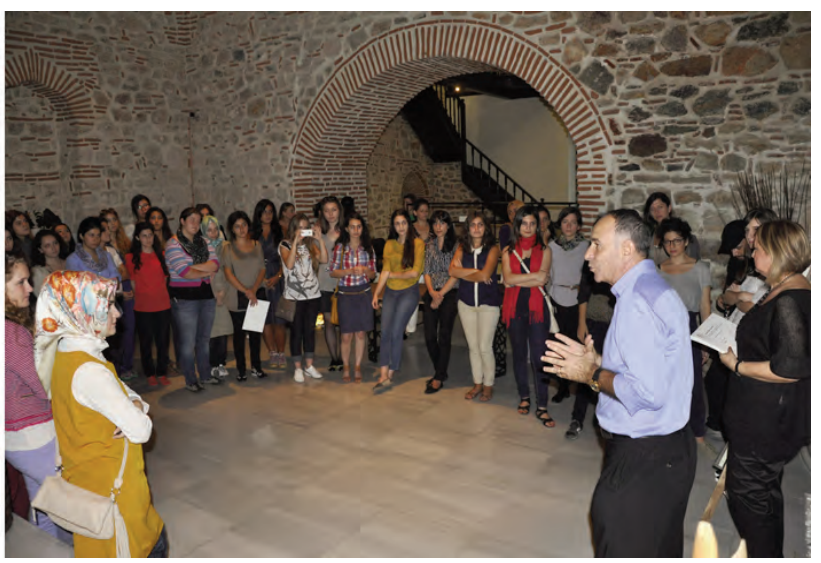

Figure 7 7. The closing session of the workshop. 
with the city actively and understand its complex and multi-layered structure.

At last but not least, the reciprocal benefits of organizing design workshops in cities with a "palimpsest" identity such as Istanbul, aiming to explore the multi-layered nature of the city, must be emphasized since it provides sources of inspiration with rich experiences for developing an understanding of the relations between global culture, transformation of cities and emergent spatial practices for the architecture students.

\section{REFERENCES}

BAR-ELI, S., AND OXMAN, R. (1998) "The Architectural Design Studio: current trends and future directions", Proceedings of Forum II: Architectural Education for the $3^{\text {rd }}$ millennium, eds: A. Şentürer, F. Özersay, Gazi Magusa, North Cyprus.

BECHHOFER, S. (2001) "Amasya: The future of tradition", $2^{\text {nd }}$ International Symposium of IAPS-CSBE Network: Traditional Environments in a new Millennium, Amasya, Turkey, 20-23 June.

CivAROĞLU, A. (2003) "Sen'in Ardından", Mimarlık, No. 310, March-April 2003.

EREN, C., AND TURGUT, H. (2001) "Scale, content and method: Different Approaches to the Design Studio in the first year of Architectural Studies, Proceedings of $30^{\text {th }}$ International Symposium, Engineering Education 2001, leuchtturm-Verlag2001 -Publication Number: 1545, pp.239-243.

LOW, S. (1992) "Changes in culture-environmental studies in architectural education in North America", IAPS $12^{\text {th }}$ Conference Proceedings.

MILLINER, L. (2003) "Architectural Education; Studio Culture", Keynote Paper, CEBE Concrete Centre Conference, December 2003, St Catherine's College, Oxford.

RAPOPORT, A. (2002) "Traditional environments, culture and preservation", $2^{\text {nd }}$. International Symposium of IAPS-CSBE Network: Traditional Environments in a new Millennium, Amasya, Turkey, 20-23 June.

RAPOPORT, A. (2008) "Some Further Thoughts On Culture And Environment," Archnet-IJAR, International Journal of Architectural Research, Volume 2(1), March 2008.

TURGUT, H., ŞENER, E., PULAT, G. AND TÜRKOĞLU, $H$. (2002) "A Design Workshop Experience in Amasya: Continuity and Change" Proceedings of $31^{\text {st }}$ International Symposium, Engineering Education, eds: V. Litvinenko, A. Melezinek, and V. Prichodko, Verlag: St. Petersburg, Vol.2, pp:552-557.

TURGUT YILDIZ, H. (2007) "Content, Scale, Method, and the Role of Place: A Design Teaching Approach", eds: Ashraf M. Salama, and Nicholas Wilkinson, Design Studio Pedagogy: Horizons for the Future, The Urban International Press, England, pp. 295-305.

TURGUT YILDIZ, H., ND INALHAN G. (2008) "Importance Of 'Place': Using Traditional and Historical Cities in Architectural Design Education", 20 ${ }^{\text {th }}$ IAPS Conference: Urban Diversities, Biosphere and well-being, Rome, Italy $28^{\text {th }}$ July- ${ }^{\text {st }}$ August 2008.
WALKER, K. (2001) Architectures of Globalization, Places Journal, Vol. 14, No.2, Fall 2001, pp. 70-73.

WARFIELD, J. (2002) “Designing in Traditional Environments: A search for New Paradigms" $2^{\text {nd }}$. International Symposium of IAPS-CSBE Network: Traditional Environments in a new Millennium, Amasya, Turkey, 20-23 June.

IKSV $1^{\text {st }}$ Istanbul Design Biennial, 13 October - 14 December 2012) Official webpage: http://istanbultasarimbienali.iksv.org IAPS - Inernational Association of Peopole-Environment Studies Official webpage: http://www.iaps-association.org 